\title{
Recent advances in preventing cardiovascular disorders by managing lipid levels Anders G Olsson
}

\author{
Address: Department of Medicine and Health, Faculty of Health Sciences, Linköping University, Linköping and Stockholm Heart Center, \\ Bergviksvägen 48, SE-167 63 Bromma, Sweden \\ Email: anders.olsson@liu.se
}

Fl000 Medicine Reports 2010, 2:66 (doi:10.3410/M2-66)

The electronic version of this article is the complete one and can be found at: http://fl000.com/reports/medicine/content/2/66

\begin{abstract}
Advances in clinical lipidology during the last 18 months include the establishment of high-sensitivity C-reactive protein (hsCRP) as an important risk marker for cardiovascular disease. Determining hsCRP levels should help the clinician single out patients at particularly high risk. However, more research needs to be done in this area. Furthermore, statins do not seem to be of benefit in patients with severe congestive heart failure, on chronic hemodialysis, or with aortic stenosis. Next, plasma triglyceride levels are now considered an important risk marker for cardiovascular disease, but the therapeutic benefits related to lowering triglyceride levels remain difficult to achieve. Also, nicotinic acid has gained more interest partly because recent studies have demonstrated positive effects on atherosclerosis development and partly because the side effect of flushing seems to be partially avoidable with the concomitant administration of laropiprant. Both the raising of high-density lipoprotein cholesterol by nicotinic acid and the additional lowering of low-density lipoprotein cholesterol by ezetimibe and eprotirome will need to demonstrate hard endpoint reductions in largescale intervention trials. Trials of niacin/laropiprant (the AIM-HIGH and HPS2-THRIVE studies) and ezetimibe (the IMPROVE-IT study) are already under way.
\end{abstract}

\section{Introduction and context}

In recent years, considerable achievements have been realized in the prevention of fighting cardiovascular disease by modifying blood lipid levels. C-reactive protein has proven to be an important additional risk indicator amenable to therapy with statins. The limitation of statin therapy has also been defined in several studies in patients with diseases that share some characteristics with atherosclerosis (e.g., aortic valve and kidney disease). Several drugs have been used in efforts to further diminish low-density lipoprotein cholesterol (LDL-C) and thereby further decrease cardiovascular risk. Triglyceride lowering in patients with diabetes has shown disappointing results. Increases in putatively cardioprotective high-density lipoprotein cholesterol (HDL-C) are evaluated in several studies.

\section{Recent advances The JUPITER study}

As high-sensitivity C-reactive protein (hsCRP) has been shown to predict cardiovascular disease [1], it has been of interest to study to what extent people with elevated hsCRP could benefit from lipid lowering. This was done in the JUPITER (Justification for the Use of Statins in Prevention: An Intervention Trial Evaluating Rosuvastatin) study [2]; 17,802 healthy men and women with LDL-C of below $130 \mathrm{mg} / \mathrm{dL}$ (3.4 mmol/L) and hsCRP of $2.0 \mathrm{mg} / \mathrm{L}$ or higher were randomly assigned to rosuvastatin $20 \mathrm{mg}$ or placebo. The hazard ratio (HR) of the primary endpoint was $0.56(P<0.00001)$. In a subsequent subgroup analysis [3], it was demonstrated that in participants who achieved LDL-C of below $70 \mathrm{mg} / \mathrm{dL}(1.8 \mathrm{mmol} / \mathrm{L})$ and hsCRP of less than $1 \mathrm{mg} / \mathrm{L}$, significant $(79 \%)$ reduction occurred. The achieved hsCRP concentrations 
were predictive of event rates irrespective of the lipid endpoint, including the apolipoprotein B to A-1 ratio.

\section{Clinical limitations of statin treatment}

Statin treatment for coronary heart disease has been very successful, as demonstrated in many large-scale interventional studies. Subgroup analyses of these studies have often indicated beneficial outcomes in diagnoses related to the primary therapeutic goal. Therefore, statin treatment has been tried in a number of diseases that are clinically close to atherosclerosis. In general, such studies have produced negative or neutral outcomes and disappointments. This was the case with a randomized control study of rosuvastatin in congestive heart failure in the CORONA (Controlled Rosuvastatin Multinational Trial in Heart Failure) study [4], although a limited effect was seen in the GISSI (Gruppo Italiano per lo Studio della Sopravvivenza nell'Infarto Miocardico) study [5] using omega-3 fatty acid as the active treatment. Further analysis of the CORONA study showed that patients in the lowest tertile of plasma amino-terminal pro-brain natriuretic peptide (NT-proBNP), a marker of cardiac dysfunction, had the best prognosis and, if assigned to rosuvastatin instead of placebo, had a greater reduction in the primary endpoint than patients in the other tertiles (heterogeneity test, $P=0.0192$ ) [6]. This reflected fewer atherothrombotic events and sudden deaths with rosuvastatin. It was concluded that patients with heart failure due to ischemic heart disease who have NT-proBNP values of less than $103 \mathrm{pmol} / \mathrm{L}(868 \mathrm{pg} / \mathrm{mL}$ ) may benefit from rosuvastatin. Also, in a retrospective hypothesisgenerating study, the CORONA authors found a significant interaction between hsCRP and the effect of rosuvastatin for most endpoints, and rosuvastatin treatment was associated with better outcomes in patients with hsCRP of at least $2.0 \mathrm{mg} / \mathrm{L}$ [7].

In the AURORA (A Study to Evaluate the Use of Rosuvastatin in Subjects on Regular Hemodialysis: An Assessment of Survival and Cardiovascular Events) study, rosuvastatin was tried in patients treated with hemodialysis because of renal failure and the outcome was neutral [8]. The AURORA study thereby confirmed what was previously seen in the 4D (Die Deutsche Diabetes Dialyse) study using atorvastatin [9]. In the SEAS (Simvastatin and Ezetimibe in Aortic Stenosis) study, statin plus ezetimibe was shown not to benefit patients with aortic stenosis [10]. However, ischemic events were positively affected by this combined LDL-Clowering treatment.

\section{Triglyceride lowering: the ACCORD study}

In a subgroup analysis of the IDEAL (Incremental Decrease in End Points Through Aggressive Lipid
Lowering) and TNT (Treating to New Target) studies, the role of triglycerides as a cardiovascular disease predictor during statin treatment was evaluated [11]. After age, gender, and study were adjusted for, risk of cardiovascular events increased with increasing triglyceride levels. Patients in the highest quintile had a rate of events that was $63 \%$ higher than that of patients in the lowest quintile (HR 1.63, 95\% confidence interval 1.461.81 ), and the relation of triglycerides to risk was apparent even within the normal range of triglycerides. However, when HDL-C, the ratio of apolipoprotein B to A-1, diabetes, body mass index, glucose, hypertension, and smoking were included in the statistical analysis, triglycerides were abolished as a significant predictor of cardiovascular events. The authors concluded that even slightly increased triglyceride levels are associated with higher risk of recurrence of cardiovascular events in statin-treated patients and should be considered a useful marker of risk.

The effect of lowering triglyceride levels on cardiovascular disease risk with a statin plus fenofibrate as compared with statin monotherapy was evaluated in patients with type 2 diabetes in the lipid arm of the ACCORD (Action to Control Cardiovascular Risk in Diabetes) study [12]. The study included 5518 patients who were followed up for 4.7 years. While LDL-C did not differ between study treatments, triglyceride levels were significantly lower and HDL-C was significantly higher in the fenofibrate-treated group. The HR of the primary cardiovascular outcome in the fenofibrate group was $0.92(P=0.32)$. Secondary outcomes did not differ either. Subgroup analysis indicated a gender difference with higher risk of cardiovascular events in women in the fenofibrate arm. Those who had high triglyceride and low HDL-C levels also seemed to do better than the others $(P=0.06)$ but this was barely significant.

\section{ARBITER 6-HALTS}

The ARBITER 6-HALTS (Arterial Biology for the Investigation of the Treatment Effects of Reducing Cholesterol 6 - High-Density Lipoprotein and Low-Density Lipoprotein Treatment Strategies) study evaluated the difference in the development of carotid intima-media thickness (CIMT) between patients treated with niacin or ezetimibe. All patients had coronary artery disease or were at high risk for such an event. They were on statin treatment and were randomly assigned to niacin or ezetimibe. The mean HDL-C increased by $18 \%$ in the niacin-treated group, and LDL-C and triglycerides were also significantly decreased. Ezetimibe lowered LDL-C by $19 \%$. Niacin significantly decreased CIMT, whereas CIMT was essentially unchanged in the ezetimibe group ( $P=0.003$ between groups). The incidence of 
major cardiovascular events was significantly lower in the niacin group than in the ezetimibe group. Will an additional decrease in LDL-C by combining ezetimibe with statin treatment add clinical benefit and be safe? The final answer to this question will have to await the publication of the IMPROVE-IT (Improved Reduction of Outcomes: Vytorin Efficacy International Trial) study [13].

\section{Tredaptive}

Niacin therapy has been available for decades but its use has been hampered because it can cause frequent flushing of the skin. The mechanism of flushing was recently elucidated, and a prostaglandin receptor blocker laropiprant was demonstrated to significantly improve this side effect [14]. Merck (Darmstadt, Germany) has developed an extended-release niacin tablet together with laropiprant and this drug combination, named Tredaptive, has proven to be efficient in improving blood lipid levels with considerably diminished flushing [15]. Tredaptive has been approved for sale in the European Union but not in the US. This therapy is now being tested for clinical efficacy and safety in a large-scale intervention study: HPS2-THRIVE (Heart Protection Study 2 Treatment of High-Density Lipoprotein to Reduce the Incidence of Vascular Events).

\section{Eprotirome}

The fact that atherosclerotic cardiovascular disease is only partially reversed by statin treatment has also prompted scientists to try to decrease LDL-C to levels that are lower than those obtained by even the most powerful statin. Ezetimibe is one example of such an effort. Another such candidate is eprotirome. Eprotirome is a thyromimetic compound that has minimal uptake in nonhepatic tissues and has affinity for the triiodothyronine receptor $\beta$ isoform, which mediates the lipid-lowering actions of thyroid hormone. This cholesterol-lowering compound is free of other thyromimetic effects. In a recent paper, it was demonstrated that 25,50 , or $100 \mu \mathrm{g}$ daily added to statin treatment for 12 weeks in patients with hypercholesterolemia further decreased LDL-C by 22\%, 28\%, and 32\%, respectively. This promising drug will need further safety and efficacy evaluations in studies with clinical endpoints as the outcome measure.

\section{Implications for clinical practice}

Recent publications within the lipid field have both expanded and limited the use of drugs affecting lipid metabolism. The JUPITER study revealed that hsCRP may be a valuable risk assessment tool and may help delineate subjects who would particularly benefit from statin treatment. It has to be kept in mind, however, that many participants in the JUPITER study already had a substantial risk, including hypertension and metabolic syndrome.

Statin treatment of patients with congestive heart failure or on chronic hemodialysis does not improve their cardiovascular risk. Furthermore, even if ischemic events did decrease in statin-treated patients with aortic stenosis, the treatment did not retard the development of the valve disease. Another limitation was revealed with fibrate treatment in type 2 diabetes; the ACCORD lipid study demonstrated a conclusion similar to that of the FIELD (Fenofibrate Intervention and Event Lowering in Diabetes) study: fenofibrate does not improve outcome when indiscriminately prescribed to patients with type 2 diabetes. On the other hand, diabetes patients with high triglyceride and low HDL levels seem to have a limited benefit from fibrate treatment.

The results of the ARBITER 6-HALTS study and the upcoming availability of Tredaptive as a niacin that causes less flushing are promising with regard to niacin as a drug to add to ongoing statin treatment. These results point to the rapidly increasing interest in elevating HDL-C to further decrease cardiovascular risk. Alternatively, two drugs may help further decrease atherogenic LDL-C: ezetimibe and eprotirome. Large endpoint studies are needed to establish these new therapies in the lipid field of cardiovascular prevention. A study of ezetimibe, the IMPROVE-IT study, is already under way.

\section{Abbreviations}

ACCORD, Action to Control Cardiovascular Risk in Diabetes; ARBITER 6-HALTS, Arterial Biology for the Investigation of the Treatment Effects of Reducing Cholesterol 6 - High-Density Lipoprotein and LowDensity Lipoprotein Treatment Strategies; AURORA, A Study to Evaluate the Use of Rosuvastatin in Subjects on Regular Hemodialysis: An Assessment of Survival and Cardiovascular Events; CIMT, carotid intima-media thickness; CORONA, Controlled Rosuvastatin Multinational Trial in Heart Failure; HDL, high-density lipoprotein; HDL-C, high-density lipoprotein cholesterol; HR, hazard ratio; hsCRP, high-sensitivity C-reactive protein; IMPROVE-IT, Improved Reduction of Outcomes: Vytorin Efficacy International Trial; JUPITER, Justification for the Use of Statins in Prevention: An Intervention Trial Evaluating Rosuvastatin; LDL-C, lowdensity lipoprotein cholesterol; NT-ProBNP, aminoterminal pro-brain natriuretic peptide.

\section{Competing interests}

AGO has received consultation fees or support for clinical trials from AstraZeneca (London, UK), Karo Bio 
AB (Huddinge, Sweden), Merck Sharp \& Dohme Corp. (a subsidiary of Merck \& Co., Whitehouse Station, NJ, USA), Pfizer Inc. (New York, NY, USA), Roche (Basel, Switzerland), and sanofi-aventis (Paris, France).

\section{References}

I. Ridker PM, Cushman M, Stampfer MJ, Tracy RP, Hennekens CH: Inflammation, aspirin, and the risk of cardiovascular disease in apparently healthy men. $N$ Engl J Med 1997, 336:973-9.

2. Ridker PM, Danielson E, Fonseca FA, Genest J, Gotto AM Jr, Kastelein JJ, Koenig W, Libby P, Lorenzatti AJ, MacFadyen JG, Nordestgaard BG, Shepherd J, Willerson JT, Glynn RJ; JUPITER Study Group: Rosuvastatin to prevent vascular events in men and women with elevated C-reactive protein. $N$ Engl J Med 2008, 359:2195-207.

Changes Clinical Practice

FI000 Factor 10.0 Exceptional

Evaluated by Melvin Cheitlin 28 Nov 2008, Seth Field 09 Feb 2009, Judy Kersten 26 Mar 2009, Conrado Estol 30 Mar 2009, Philipp M Lepper 08 Apr 2009

3. Ridker PM, Danielson E, Fonseca FA, Genest J, Gotto AM Jr, Kastelein JJ, Koenig W, Libby P, Lorenzatti AJ, Macfadyen JG, Nordestgaard BG, Shepherd J, Willerson JT, Glynn RJ; JUPITER Trial Study Group: Reduction in C-reactive protein and LDL cholesterol and cardiovascular event rates after initiation of rosuvastatin: a prospective study of the JUPITER trial. Lancet 2009, 373: $1175-82$.

4. Kjekshus J, Apetrei E, Barrios V, Böhm M, Cleland JG, Cornel JH, Dunselman P, Fonseca C, Goudev A, Grande P, Gullestad L, Hjalmarson A, Hradec J, Jánosi A, Kamenský G, Komajda M, Korewicki J, Kuusi T, Mach F, Mareev V, McMurray J], Ranjith N, Schaufelberger M, Vanhaecke J, van Veldhuisen DJ, Waagstein F, Wedel $\mathrm{H}$, Wikstrand J; CORONA Group: Rosuvastatin in older patients with systolic heart failure. N EnglJ Med 2007, 357:2248-6I.

FI000 Factor 6.6 Must Read

Evaluated by Jerome Fleg 2I Nov 2007, Wilbert Aronow 27 Nov 2007, Melvin Cheitlin 16 Sep 2008

5. Gissi-HF Investigators, Tavazzi L, Maggioni AP, Marchioli R, Barlera S, Franzosi MG, Latini R, Lucci D, Nicolosi GL, Porcu M, Tognoni G: Effect of rosuvastatin in patients with chronic heart failure (the GISSI-HF trial): a randomised, double-blind, placebocontrolled trial. Lancet 2008, 372:123|-9.

6. Cleland JG, McMurray J], Kjekshus J, Cornel JH, Dunselman P, Fonseca C, Hjalmarson A, Korewicki J, Lindberg M, Ranjith N, van Veldhuisen DJ, Waagstein F, Wedel H, Wikstrand J; CORONA Study Group: Plasma concentration of amino-terminal pro-brain natriuretic peptide in chronic heart failure: prediction of cardiovascular events and interaction with the effects of rosuvastatin: a report from CORONA (Controlled Rosuvastatin Multinational Trial in Heart Failure). J Am Coll Cardiol 2009, 54:1850-9.

7. McMurray JJ, Kjekshus J, Gullestad L, Dunselman P, Hjalmarson A, Wedel H, Lindberg M, Waagstein F, Grande P, Hradec J, Kamenský G, Korewicki J, Kuusi T, Mach F, Ranjith N, Wikstrand J; CORONA Study Group: Effects of statin therapy according to plasma high-sensitivity C-reactive protein concentration in the Controlled Rosuvastatin Multinational Trial in Heart Failure
(CORONA): a retrospective analysis. Circulation 2009, 120:2188-96.

8. Fellström BC, Jardine AG, Schmieder RE, Holdaas H, Bannister K, Beutler J, Chae DW, Chevaile A, Cobbe SM, Grönhagen-Riska C, De Lima J], Lins R, Mayer G, McMahon AW, Parving HH, Remuzzi G, Samuelsson O, Sonkodi S, Sci D, Süleymanlar G, Tsakiris D, Tesar V, Todorov V, Wiecek A, Wüthrich RP, Gottlow M, Johnsson E, Zannad F; AURORA Study Group: Rosuvastatin and cardiovascular events in patients undergoing hemodialysis. N Engl J Med 2009, 360:1395-407.

Changes Clinical Practice

FI000 Factor 8.0 Exceptional

Evaluated by Ihab Wahba II May 2009, Peter Stenvinkel 14 May 2009

9. Wanner C, Krane V, März W, Olschewski M, Mann JF, Ruf G, Ritz E; German Diabetes and Dialysis Study Investigators: Atorvastatin in patients with type 2 diabetes mellitus undergoing hemodialysis. N Engl J Med 2005, 353:238-48.

10. Rossebø AB, Pedersen TR, Boman K, Brudi P, Chambers JB, Egstrup K, Gerdts E, Gohlke-Bärwolf C, Holme I, Kesäniemi YA, Malbecq W, Nienaber CA, Ray S, Skjaerpe T, Wachtell K, Willenheimer R; SEAS Investigators: Intensive lipid lowering with simvastatin and ezetimibe in aortic stenosis. N Engl J Med 2008, 359:1343-56.

FI000 Factor 6.4 Must Read Evaluated by John Paraskos 10 Oct 2008, Jerome Fleg 16 Oct 2008

II. Faergeman O, Holme I, Fayyad R, Bhatia S, Grundy SM, Kastelein J], LaRosa JC, Larsen ML, Lindahl C, Olsson AG, Tikkanen MJ, Waters DD, Pedersen TR; Steering Committees of IDEAL and TNT Trials: Plasma triglycerides and cardiovascular events in the Treating to New Targets and Incremental Decrease in Endpoints through Aggressive Lipid Lowering trials of statins in patients with coronary artery disease. Am J Cardiol 2009, 104:459-63.

12. ACCORD Study Group, Ginsberg HN, Elam MB, Lovato LC, Crouse JR 3rd, Leiter LA, Linz P, Friedewald WT, Buse JB, Gerstein HC, Probstfield J, Grimm RH, Ismail-Beigi F, Bigger JT, Goff DC Jr, Cushman WC, Simons-Morton DG, Byington RP: Effects of combination lipid therapy in type 2 diabetes mellitus. N Engl J Med 2010, 362:I563-74.

13. Cannon CP, Giugliano RP, Blazing MA, Harrington RA, Peterson JL, Sisk CM, Strony J, Musliner TA, McCabe CH, Veltri E, Braunwald E, Califf RM; IMPROVE-IT Investigators: Rationale and design of IMPROVE-IT (IMProved Reduction of Outcomes: Vytorin Efficacy International Trial): comparison of ezetimbe/simvastatin versus simvastatin monotherapy on cardiovascular outcomes in patients with acute coronary syndromes. Am Heart J 2008, 156:826-32.

14. Cheng K, Wu TJ, Wu KK, Sturino C, Metters K, Gottesdiener K, Wright SD, Wang Z, O'Neill G, Lai E, Waters MG: Antagonism of the prostaglandin D2 receptor I suppresses nicotinic acidinduced vasodilation in mice and humans. Proc Natl Acad Sci U S A 2006, 103:6682-7.

15. Maccubbin D, Bays HE, Olsson AG, Elinoff $V$, Elis A, Mitchel $Y$, Sirah W, Betteridge A, Reyes R, Yu Q, Kuznetsova O, Sisk CM, Pasternak RC, Paolini JF: Lipid-modifying efficacy and tolerability of extended-release niacin/laropiprant in patients with primary hypercholesterolaemia or mixed dyslipidaemia. Intl J Clin Prac 2008, 62:1959-70. 